\title{
Prognostic value of daytime heart rate, blood pressure, their products and quotients in chronic heart failure
}

\author{
Anna Kowalczys, Michal Bohdan, Marcin Gruchala
}

First Department of Cardiology, Medical University of Gdansk, Poland

\begin{abstract}
Background: Chronic heart failure (CHF) is an important epidemiological and therapeuthic issue with poor prognosis. The aim of the study was to estimate the prognostic value of daytime heart rate (HR), blood pressure (BP), their products and quotients in patients with CHF.

Methods: The study included 80 stable patients with CHF and reduced left ventricular ejection fraction (LVEF $\leq 35 \%)$. Physical examination, laboratory blood tests, electrocardiogram, chest X-ray, echocardiography, 6-minute walk test, telemetry monitoring and BP measurements were performed in all participants. We estimated mean daytime: BP, HR, their products and quotients. The follow-up period was 6 months. Major adverse cardiac events (MACE) included: death, cardiovascular death, hospitalization due to CHF exacerbation.

Results: The analysis involved all recruited patients with $\mathrm{CHF}$ (91\% men) aged $59 \pm 12$ years, in New York Heart Association class $2.15 \pm 0.57$ and reduced LVEF (mean LVEF: $23 \pm 6 \%$ ). The 3-month and 6-month mortality rates were $4 \%$ and $6 \%$, respectively. There was a significant correlation between diastolic blood pressure $(D B P)$, all-cause mortality $(p=0.048)$ and CHF decompensation $(p=0.0004)$ after 3-month observation period. No relationship was found between HR or systolic blood pressure $(S B P)$ and MACE. Both higher $S B P \times H R$ and $D B P \times H R$ products were related to lower risk of heart failure exacerbations during 6 -month follow-up. None of the analyzed products or ratios had an impact on mortality in this study group.
\end{abstract}

Conclusions: Diastolic blood pressure, $S B P \times H R$ and $D B P \times H R$ products may be useful in subsequent heart failure exacerbation risk stratification. Moreover, DBP value may predict short-term mortality in patients with CHF. (Cardiol J 2019; 26, 1: 20-28)

Key words: chronic heart failure, heart rate, blood pressure, diastolic blood pressure, double product

\section{Introduction}

The management of patients suffering from chronic heart failure $(\mathrm{CHF})$ is one of the most challenging issues in cardiology today. Due to the ageing of world populations, advances in acute coronary syndrome treatment and effective secondary prevention, the prevalence of $\mathrm{CHF}$ increases systematically [1]. The incidence of CHF is particularly high in elderly people. More than $50 \%$ of patients with new onset $\mathrm{HF}$ is $\geq 75$ years old [2]. Despite improvements in pharmacological and invasive therapy of $\mathrm{HF}$ the prognosis still remains poor. There are many risk factors leading to $\mathrm{HF}$ development and progression [1]. Nevertheless, the search for biomarkers and factors are useful in CHF outcome prediction not only to be able to stratify the risk but also to improve quality of life, decrease the number of subsequent hospitalizations and mortality rates [3].

Address for correspondence: Anna Kowalczys, MD, First Department of Cardiology, Medical University of Gdansk, ul. Dębinki 7, 80-211 Gdańsk, Poland, tel: +48 5834925 00, fax: +48 5834612 01, e-mail: anna.roz@gumed.edu.pl Received: 15.05.2017 Accepted: 7.09.2017 
Hypertension (HTN) is a most important cardiovascular risk factor and apart from stroke, heart failure (HF) is one of the most frequent complications of HTN [1]. Optimal blood pressure (BP) control in hypertensive patients may significantly delay HF onset and is possible using pharmacological and non-pharmacological treatment. Unfortunatelly, the rate of successful implementation of non-pharmacological treatment is low even in patients with diagnosed HTN $[1,4]$. Conversely to the general population, patients with CHF usually do not benefit from intensive antihypertensive therapy [5-7]. As a result of standard pharmacotherapy including angiotensin converting enzyme (ACE) inhibitors or angiotensin receptors blockers (ARB), beta-blockers, mineralocorticoid receptors antagonists (MRA) and diuretics, the majority of patients with $\mathrm{HF}$ and reduced left ventricular ejection fraction (HFrEF) have low or even very low BP values. Moreover, the phenomenon of the J-shaped mortality curve in the other group of patients with cardiovascular diseases was observed, which may also be apparent in the HF population. SPRINT Research Group revealed that among patients at high risk for cardiovascular events but without diabetes, targeting systolic blood pressure (SBP) of less than $120 \mathrm{mmHg}$, as compared with less than $140 \mathrm{mmHg}$, resulted in lower rates of fatal and nonfatal major cardiovascular events and death from any cause. Nevertheless, significantly higher rates of some adverse events were observed in the intensivetreatment group [8]. Bavishi et al. [9] observed that in older hypertensive patients, intensive BP control decreased cardiovascular mortality and HF, although they had increased risk of renal failure. One of the most difficult challenges in the treatment of patients with $\mathrm{CHF}$ are recurrent exacerbations of this disease. Prior hospitalization is one of the important risk factors predicting subsequent episodes of CHF decompensation [10]. The relationship between $\mathrm{BP}$ and risk for $\mathrm{CHF}$ decompensation has not been clearly established. Thus, the influence of $\mathrm{BP}$ on prognosis of patients with $\mathrm{CHF}$ remains uncertain and requires additional studies.

Heart rate (HR) is an independent cardiovascular risk factor in the general population [11]. Data from many trials demonstrated relationship between increased resting $\mathrm{HR}$ and mortality in the majority of cardiovascular diseases [12, 13]. Other studies have confirmed the positive role of HR in lowering cardiac event prevention. Heart failure involves many compensation mechanisms leading to an HR increase. Many authors have observed the correlation between increased HR and higher risk of major adverse cardiac events (MACE) in patients with CHF $[1,14]$. Nevertheless, its role in $\mathrm{HF}$ needs further investigation.

Double product (DP), defined as HR multiplied by SBP reflects myocardial oxygen consumption. Thus, it plays an important role in cardiovascular risk stratification during exercise testing in patients with ischemic heart disease $[15,16]$. There are many conflicting studies concerning the role of DP in cardiovascular risk stratification in healthy populations and hypertensive patients. According to some data, DP correlates positively with mortality in the general population [17]. However other authors discourage the use of DP as a cardiovascular risk prediction determinant [18]. The impact of DP as well as other HR and BP products and ratios on prognoses in patients with $\mathrm{CHF}$ needs further study.

The aim of this prospective study was to evaluate the prognostic value of daytime HR, BP, their products and ratios in stable patients with $\mathrm{CHF}$ in providing useful, achievable tools in risk stratification.

\section{Methods}

There were 80 stable patients with $\mathrm{CHF}$ and HFrEF enrolled in this study. The inclusion criteria were as follows: age $18-80$ years, stable clinical status, CHF diagnosed at least 1 year before recruitment into the study, ischemic or dilated cardiomyopathy, $\mathrm{LVEF} \leq 35 \%$ and optimal medical therapy. The exclusion criteria were as follows: CHF exacerbation within 3 months prior to the study, pregnancy and valvular heart disease as a cause of CHF. All patients recruited were diagnosed and treated at the Cardiology Department according to the recent 2016 European Society of Cardiology (ESC) Guidelines for the diagnosis and treatment of acute $\mathrm{HF}$ and CHF [1]. All patients underwent following examinations: medical history, physical examination, laboratory tests, 12-lead resting electrocardiogram (ECG), chest X-ray, transthoracic echocardiography and the 6-minute walk test. Laboratory tests including the following parameters were assessed: total blood count with hemoglobin and red blood cell distribution width, sodium, potassium, urea, creatinine, glomerular filtration rate, total bilirubin, cholesterol, triglycerides, uric acid, alanine transaminase, aspartate transaminase, glucose and B-type natriuretic peptide.

Heart rate and BP obtained were mean daytime values as determined through measurements 
performed with 24-h telemetry monitoring and OMRON M7 Intelli IT device (Japan), 4 times a day, respectively. BP was measured at rest, each time twice with a 2 min pause at $6.00,10.00$, 16.00 and 20.00 h. For analysis of median value all 8 measurements was taken. Pulse pressure (PP) values were calculated as the difference between SBP and DBP. The following products were also estimated and ratios: $\mathrm{HR} \times \mathrm{SBP}(\mathrm{DP}), \mathrm{HR} \times \mathrm{DBP}$, $\mathrm{HR} \times \mathrm{PP}, \mathrm{HR} / \mathrm{SBP}, \mathrm{HR} / \mathrm{DBP}, \mathrm{HR} / \mathrm{PP}$. The followup period was 6 months. All follow-up data were obtained from visits or by telephone. MACE was defined as: death of all causes, cardiovascular death, hospitalization due to the HF exacerbation. The study protocol was approved by the Local Ethics Committee.

\section{Statistical analysis}

All statistical calculations were performed using the statistical package StatSoft. Inc. (2014) STATISTICA (data analysis software system), version 12.0. Quantitative variables were characterized by the arithmetic mean, standard deviation, median, minimum and maximum values (range) and 95\% confidence interval (CI). Whereas qualitative variables were presented using frequencies and percentages. To check whether a variable quantitative came from a normally distributed population analysis using the Shapiro-Wilk. In contrast, testing the hypothesis of equal variances test, Leven (Brown-Forsythe) was used. The significance of differences between the two groups (model variables unrelated) examined these test significance differences: Student t or, in the absence of homogeneity of variance, the Welch test or Mann-Whitney $\mathrm{U}$ (in cases of non-compliance with the conditions of applicability of the Student $t$ test or for variables measured on the ordinal scale). Tests of independence $\chi^{2}$ was used for categorical variables (by using Yates correction according to the number of cells below 10, checking conditions of Cochran and the Fisher exact test). In order to establish link strength and direction between variables, correlation analysis was used in calculating the Pearson correlation coefficients and/or Spearman. In all calculations the level of significance was set at $\mathrm{p}=0.05$.

\section{Results}

Data of all 80 recruited patients were under analysis. The basic characteristics of the study population are presented in Tables 1 and 2 .

The mean age of the study group was $59 \pm$ \pm 11 years and men constituted the majority of the
Table 1. Baseline characteristics of the study group.

\begin{tabular}{|c|c|}
\hline Variables & Values \\
\hline Age [year] & $59 \pm 12$ \\
\hline Men & $93(91 \%)$ \\
\hline BMI $\left[\mathrm{kg} / \mathrm{m}^{2}\right]$ & $28.7 \pm 5.4$ \\
\hline NYHA class & $2.15 \pm 0.57$ \\
\hline Heart rate $[\mathrm{bpm}]$ & $75 \pm 14.3$ \\
\hline $\mathrm{SBP}[\mathrm{mmHg}]$ & $114 \pm 14$ \\
\hline $\mathrm{DBP}[\mathrm{mmHg}]$ & $70 \pm 9.5$ \\
\hline $\mathrm{DP}[\mathrm{bpm} \times \mathrm{mmHg}]$ & $8649 \pm 1953.5$ \\
\hline $\mathrm{HR} \times \mathrm{DBP}[\mathrm{bpm} \times \mathrm{mmHg}]$ & $5368 \pm 1303.6$ \\
\hline $\mathrm{HR} \times \mathrm{PP}[\mathrm{bpm} \times \mathrm{mmHg}]$ & $3272 \pm 1066$ \\
\hline $\mathrm{HR} / \mathrm{SBP}[\mathrm{bpm} / \mathrm{mmHg}]$ & $0.67 \pm 0.15$ \\
\hline HR/DBP [bpm/mmHg] & $1.08 \pm 0.24$ \\
\hline HR/PP [bpm/mmHg] & $1.94 \pm 0.97$ \\
\hline LVEF [\%] & $23.3 \pm 6.7$ \\
\hline 6MWT distance [m] & $351.3 \pm 110.3$ \\
\hline Ischemic CHF & $50(62.5 \%)$ \\
\hline Prior MI & $50(62.5 \%)$ \\
\hline Prior stroke & $10(12.5 \%)$ \\
\hline Prior CABG & $13(16.25 \%)$ \\
\hline Prior PCl & $30(37.5 \%)$ \\
\hline Prior ICD & $49(61.25 \%)$ \\
\hline Smoking & $55(68.75 \%)$ \\
\hline Qualified to HTX & $9(11 \%)$ \\
\hline BNP $[p g / m L]$ & $742 \pm 701$ \\
\hline
\end{tabular}

Values are presented as means \pm standard derivation or as number (percentages); BMI — body mass index; NYHA — New York Heart Association; SBP - systolic blood pressure; DBP — diastolic blood pressure; DP - double product; HR - heart rate; PP - pulse pressure; LVEF — left ventricular ejection fraction; 6MWT — six-minute walk test; CHF — chronic heart failure; MI - myocardial infarction; CABG - coronary artery bypass grafting; $\mathrm{PCl}$ - percutaneous coronary interventions; ICD — impantable cardioverter defibrillator; HTX - heart transplantation; BNP - B-type natriuretic peptide

population (91\%). Most participants were in New York Heart Association (NYHA) II class (mean: $2.2 \pm 0.6)$. The majority of recruited subjects were nondiabetic $(70 \%)$ and had $\mathrm{CHF}$ of ischemic origin $(62.5 \%)$. Atrial fibrillation was confirmed in $22 \%$ of all study participants. For a majority of study population, comorbidities were reported. Three (4\%) patients died during 3-month followup, and $5(6 \%)$ during a 6 -month observation due to HF deterioration. Ten (12.7\%) patients were subsequently hospitalized for CHF decompensation within 3-months and 19 (24\%) during 6 month follow-up.

After a 3-month and excluding a 6 month observation period there was a significant correlation 
Table 2. Comorbidities and medication use at baseline.

\begin{tabular}{lc}
\hline Variables & Values \\
\hline Hypertension & $50(62.5 \%)$ \\
Atrial fibrillation & $16(22 \%)$ \\
Diabetes mellitus & $24(30 \%)$ \\
Dyslipidemia & $26(32.5 \%)$ \\
COPD & $17(21.25 \%)$ \\
Liver dysfunction & $9(11.25 \%)$ \\
Renal dysfunction & $16(20 \%)$ \\
Thyroid dysfunction & $11(13.25 \%)$ \\
Peptic ulcer disease & $7(8.75 \%)$ \\
Peripheral arterial disease & $5(6.25 \%)$ \\
ASA & $41(51.25 \%)$ \\
Oral anticoagulatnts & $9(11 \%)$ \\
Beta-blockers & $75(93.75 \%)$ \\
Amiodarone & $19(23.75 \%)$ \\
Ivabradine & $5(6.25 \%)$ \\
Loop diuretics & $75(93.75 \%)$ \\
Aldosterone antagonists & $12(15 \%)$ \\
ACE inhibitors & $70(87.25 \%)$ \\
Statins & $55(68.75 \%)$ \\
ARB & $10(12.5 \%)$ \\
Digoxine & $14(17.5 \%)$ \\
\hline
\end{tabular}

Values are presented as numbers (percentages); COPD — chronic obstructive pulmonary disease; ASA — acetylsalicylic acid; ACE angiotensin converting enzyme; $\mathrm{ARB}$ - angiotensin receptor blockers

between DBP and all-cause mortality $(\mathrm{p}=0.048)$ as well as CHF decompensation $(\mathrm{p}=0.0004)$ in the whole group. DBP was significantly higher in patients without CHF decompensation as well as in those who survived. No relationship was found between HR or SBP and MACE. Furthermore, it was observed that in patients with higher $\mathrm{HR} \times$ $\times \mathrm{DBP}$ product, risk of $\mathrm{CHF}$ decompensation was significantly lower in both 3 -month $(\mathrm{p}=0.001)$ and 6 -month $(\mathrm{p}=0.032)$ observation periods. Moreover, patients hospitalized for CHF exacerbation in 6-month observation DP was significantly lower than in stable ones. No correlations were found between: $\mathrm{DP}, \mathrm{HR} \times \mathrm{DBP}, \mathrm{HR} \times \mathrm{PP}$ products and 3 or 6 month mortality. None of the following calculated quotients: HR/SBP, HR/DBP, HR/PP significantly influenced the risk of $\mathrm{CHF}$ exacerbation or mortality. None of the presented factors were found to be significant for MACE risk stratification in multiple analysis of COX proportional hazard. The most significant correlations are presented in Tables 3 and 4.

\section{Discussion}

In this prospective study, it was demonstrated that daytime DBP may be a valuable risk stratification factor for death and HF exacerbation in stable patients with CHF. Within the present study population mean SBP and DBP values were $114 \pm 14$ $\mathrm{mmHg}$ and $70 \pm 9.5 \mathrm{mmHg}$, respectively. It was shown that higher DBP but not SBP was associated with lower risk of death and $\mathrm{CHF}$ decompensation in the 3-month observation period. A relationship was not confirmed between DBP and MACE in the 6 -month observation period. It was presumed that this fact may be related to patient clinical status improvement during the follow-up period. Similar observations concerning DBP in HF have been reported in other previous studies. Lee et al. [5] in restrospective analysis of Digitalis Investigation Group (DIG) data revealed that in patients with systolic dysfunction (LVEF $\leq 45 \%)$ and NYHA II and III class, lower SBP and DBP were associated with greater mortality in short and long-term observation. This study supports the suggestion of other authors that patients with SBP $<110$ $\mathrm{mmHg}$ and $\mathrm{DBP}<60 \mathrm{mmHg}$ had a significantly higher risk of death. These observations have been documented in several studies. According to these authors, patients with SBP $<110 \mathrm{mmHg}$ were at higher risk of mortality $[19,20]$. The negative correlation between $\mathrm{BP}$ and mortality was also observed in a prospective study of patients with acute HF decompensation performed by Ghali et al. [21]. Lip et al. [22] A recent cohort study indicated that patients with incident $\mathrm{HF}$ and increased initial SBP and DBP values were at higher risk of adverse cardiovascular events. Similarly, Raphael et al. [6] revealed that contrary to the general population, higher SBP was a favourable prognostic marker in $\mathrm{CHF}$ which was not related to etiology, ACE inhibitor or beta-blocker use. Some authors have suggested that low daytime BP variability may also influence prognosis in patients with HF [23]. Sherazi et al. [24] and revealed that the absence of hypertension, as well as elevated urea and lower $\mathrm{LVEF} \leq 45 \%$ indicate increased risk of short and long-term mortality. The relationship between DBP and MACE has been discussed in other publications concerning this subject $[8,25,26]$. McEvoy et al. [27] revealed an association between DBP $<60 \mathrm{mmHg}$ and coronary heart disease events in Atherosclerosis Risk In Communities (ARIC) cohort study population. It has been documented that low DBP was related to subclinical myocardial damage and MACE. The most important conse- 
Table 3. Correlations between chosen variables and 3-month mortality rate.

\begin{tabular}{|c|c|c|c|}
\hline Variable & Survival $(n=77)$ & Death $(n=3)$ & $\mathbf{P}$ \\
\hline \multicolumn{4}{|l|}{ HR } \\
\hline Mean (SD) & $76.0(14.0)$ & $69.7(24.6)$ & 0.8792 \\
\hline Range & $51.0-120.0$ & $42.0-89.0$ & \\
\hline Median & 75.0 & 78.0 & \\
\hline $95 \% \mathrm{Cl}$ & {$[72.8 ; 79.1]$} & {$[8.6 ; 130.7]$} & \\
\hline \multicolumn{4}{|l|}{ SBP } \\
\hline Mean (SD) & $114.6(14.7)$ & $103.3(9.5)$ & 0.1795 \\
\hline Range & $90.0-145.0$ & $96.0-114.0$ & \\
\hline Median & 110.0 & 100.0 & \\
\hline $95 \% \mathrm{Cl}$ & {$[111.3 ; 118.0]$} & {$[79.9 ; 126.8]$} & \\
\hline \multicolumn{4}{|l|}{ DBP } \\
\hline Mean (SD) & $71.1(9.4)$ & $59.3(9.0)$ & 0.0482 \\
\hline Range & $50.0-89.0$ & $50.0-68.0$ & \\
\hline Median & 70.0 & 60.0 & \\
\hline $95 \% \mathrm{Cl}$ & {$[69.0 ; 73.3]$} & {$[36.9 ; 81.7]$} & \\
\hline \multicolumn{4}{|l|}{ DP } \\
\hline Mean (SD) & $8691.3(1909.4)$ & $7326.0(3084.4)$ & 0.5022 \\
\hline Range & 5400.0-15600.0 & $4032.0-10146.0$ & \\
\hline Median & 8280.0 & 7800.0 & \\
\hline $95 \% \mathrm{Cl}$ & [8258.0;9124.7] & {$[-336.2 ; 14988.2]$} & \\
\hline \multicolumn{4}{|l|}{$H R \times D B P$} \\
\hline Mean (SD) & $5410.5(1269.6)$ & $4277.3(2006.5)$ & 0.3488 \\
\hline Range & $3000.0-9600.0$ & $2100.0-6052.0$ & \\
\hline Median & 5304.0 & 4680.0 & \\
\hline $95 \%$ ci & [5122.4;5698.7] & {$[-707.2 ; 9261.8]$} & \\
\hline \multicolumn{4}{|l|}{$H R \times P P$} \\
\hline Mean (SD) & 3280.8 (1071.5) & 3048.7 (1082.8) & 0.8296 \\
\hline Range & $900.0-6300.0$ & $1932.0-4094.0$ & \\
\hline Median & 3000.0 & 3120.0 & \\
\hline $95 \% \mathrm{Cl}$ & [3037.6;3524.0] & [358.9;5738.4] & \\
\hline \multicolumn{4}{|l|}{ HR/SBP } \\
\hline Mean (SD) & $0.68(0.16)$ & $0.67(0.20)$ & 0.7903 \\
\hline Mean (SD) & $0.41-1.10$ & $0.44-0.78$ & \\
\hline Range & 0.66 & 0.78 & \\
\hline Median & {$[0.64 ; 0.71]$} & {$[0.17 ; 1.16]$} & \\
\hline \multicolumn{4}{|l|}{ HR/DBP } \\
\hline Mean (SD) & $1.09(0.24)$ & $1.15(0.27)$ & 0.5861 \\
\hline Range & $0.64-1.83$ & $0.84-1.31$ & \\
\hline Median & 1.07 & 1.30 & \\
\hline $95 \% \mathrm{Cl}$ & {$[1.03 ; 1.14]$} & {$[0.48 ; 1.82]$} & \\
\hline \multicolumn{4}{|l|}{ HR/PP } \\
\hline Mean (SD) & $1.95(0.99)$ & $1.60(0.59)$ & 0.6761 \\
\hline Range & $0.98-8.08$ & $0.91-1.95$ & \\
\hline Median & 1.75 & 1.93 & \\
\hline $95 \% \mathrm{Cl}$ & {$[1.73 ; 2.18]$} & {$[0.12 ; 3.08]$} & \\
\hline
\end{tabular}

$\mathrm{SD}$ - standard derivation; $\mathrm{Cl}$ - confidence interval, other abbreviations - see Table 1 
Table 4. Correlations between chosen variables and 3-month chronic heart failure (CHF) exacerbations.

\begin{tabular}{|c|c|c|c|}
\hline Variable & No CHF decompensation ( $n=61$ ) & CHF decompensation ( $n=19$ ) & $\mathbf{P}$ \\
\hline \multicolumn{4}{|l|}{ HR } \\
\hline Mean (SD) & $76.5(14.3)$ & $69.2(13.3)$ & 0.2183 \\
\hline Range & $51.0-120.0$ & $42.0-89.0$ & \\
\hline Median & 75.0 & 70.0 & \\
\hline $95 \% \mathrm{Cl}$ & {$[73.0 ; 79.9]$} & {$[59.7 ; 78.7]$} & \\
\hline \multicolumn{4}{|l|}{ SBP } \\
\hline Mean (SD) & $115.3(15.1)$ & $107.0(10.4)$ & 0.1097 \\
\hline Range & $90.0-145.0$ & $96.0-130.0$ & \\
\hline Median & 115.0 & 102.0 & \\
\hline $95 \% \mathrm{Cl}$ & {$[111.7 ; 118.9]$} & {$[99.5 ; 114.5]$} & \\
\hline \multicolumn{4}{|l|}{ DBP } \\
\hline Mean (SD) & $72.1(9.3)$ & $60.7(5.8)$ & 0.0004 \\
\hline Range & $50.0-89.0$ & $50.0-70.0$ & \\
\hline Median & 70.0 & 60.0 & \\
\hline $95 \% \mathrm{Cl}$ & {$[69.8 ; 74.3]$} & {$[56.6 ; 64.8]$} & \\
\hline \multicolumn{4}{|l|}{ DP } \\
\hline Mean (SD) & 8796.7 (1947.2) & $7434.2(1694.1)$ & 0.0525 \\
\hline Range & 5400.0-15600.0 & 4032.0-10146.0 & \\
\hline Median & 8300.0 & 7500.0 & \\
\hline $95 \% \mathrm{Cl}$ & [8328.9;9264.4] & {$[6222.3 ; 8646.1]$} & \\
\hline \multicolumn{4}{|l|}{$H R \times D B P$} \\
\hline Mean (SD) & $5511.7(1265.1)$ & 4229.7 (993.3) & 0.0011 \\
\hline Range & $3000.0-9600.0$ & $2100.0-6052.0$ & \\
\hline Median & 5394.0 & 4477.5 & \\
\hline $95 \% \mathrm{Cl}$ & [5207.8;5 815.6] & [3519.2;4940.2] & \\
\hline \multicolumn{4}{|l|}{$\mathrm{HR} \times \mathrm{PP}$} \\
\hline Mean (SD) & 3285.0 (1107.7) & 3204.5 (830.9) & 0.9061 \\
\hline Range & $900.0-6300.0$ & 1932.0-4779.0 & \\
\hline Median & 3000.0 & 3000.0 & \\
\hline $95 \% \mathrm{Cl}$ & [3018.9; 3551.1] & {$[2610.1 ; 3798.9]$} & \\
\hline \multicolumn{4}{|l|}{ HR/SBP } \\
\hline Mean (SD) & $0.68(0.16)$ & $0.65(0.12)$ & 0.8712 \\
\hline Range & $0.41-1.10$ & $0.44-0.78$ & \\
\hline Median & 0.66 & 0.67 & \\
\hline $95 \% \mathrm{Cl}$ & {$[0.64 ; 0.72]$} & {$[0.56 ; 0.74]$} & \\
\hline \multicolumn{4}{|l|}{ HR/DBP } \\
\hline Mean (SD) & $1.08(0.25)$ & $1.14(0.21)$ & 0.3925 \\
\hline Range & $0.64-1.83$ & $0.84-1.47$ & \\
\hline Median & 1.07 & 1.17 & \\
\hline $95 \% \mathrm{Cl}$ & {$[1.02 ; 1.14]$} & {$[0.99 ; 1.29]$} & \\
\hline \multicolumn{4}{|l|}{ HR/PP } \\
\hline Mean (SD) & $1.99(1.03)$ & $1.53(0.37)$ & 0.1548 \\
\hline Range & $0.98-8.08$ & $0.91-1.95$ & \\
\hline Median & 1.75 & 1.51 & \\
\hline $95 \% \mathrm{Cl}$ & {$[1.74 ; 2.24]$} & {$[1.26 ; 1.80]$} & \\
\hline
\end{tabular}

$\mathrm{SD}$ - standard derivation; $\mathrm{Cl}$ - confidence interval, other abbreviations - see Table 1 
quence of DBP lowering is coronary blood flow reduction due to a lower perfusion gradient [27]. These mechanisms may be also present in patients with $\mathrm{HF}$ of ischemic origin. The present findings support previous hypotheses that excessive hypotensive therapy in patients with HF leading to significant BP lowering may correlate with an increase in mortality rate. Some authors however, have not confirmed DBP association with mortality but only SBP with nonsudden cardiac death [7]. In contrast to our findings concerning the influence of $\mathrm{DBP}$ on CHF exacerbations, the most recent report by Voors et al. [28] noted an association between lower SBP but not DBP and hospitalizations owing to HF. Moreover, BP was not one of the strongest predictors of mortality due to HF. According to BARDICHE-index authors lower SBP was associated with higher HF exacerbation rate independently of LVEF [29]. Several authors have demonstrated that higher SBP was independently related to improved cardiovascular survival in patients with CHF $[13,21$, $24,30]$. Surprisingly, this study did not confirm the relationship between SBP and MACE in the whole group of patients or in study subgroups. Nevertheless, it should be underlined that in contrast to other studies only mean daytime values of SBP were taken into analysis. Furthermore, the examined group was small and observation period short. In the majority of studies examining this subject follow-up duration exceeded 1 year.

It has been documented that HR is an independent risk factor in patients with HF. Elevated resting HR is associated with unfavourable patomechanisms including: increased oxygen demand, diminuated ventricular relaxation and reduced stroke volume [31]. Many authors have revealed that HR reduction impacted favourably on outcome in patients with HF [31-34]. According to the SHIFT study and substudy results, reduced HR was associated with relative risk reduction for cardiovascular death and/or HF worsening. Furthermore, lower HR was related to reversal of cardiac remodeling $[14,35]$. A recent report by Zou et al. [36] noted that HR deceleration and acceleration capacities are independent risk factors for dilated cardiomyopathies. Moreover, HR acceleration may be a valuable $\mathrm{HF}$ exacerbation prognostic factor. Nevertheless, HR reduction in patients with chronic HFrEF is not associated with better survival in atrial fibrillation presence [37, 38]. This study did not observe a significant correlation between daytime $\mathrm{HR}$ and mortality or $\mathrm{HF}$ decompensation rate in short-term observation. It cannot be excluded, however, that prolonged observation and/or mean whole day HR values would have influenced the final results. Moreover, all patients were on optimal pharmacological treatment affecting BP and HR.

In summary, according to many authors the prognostic role of BP and HR in HF outcome cannot be overestimated. Some authors have suggested that combining HF and SBP constitutes a valuable prognostic factor in older patients with HF [39]. Nevertheless, there are still few reports concerning the prognostic value of $\mathrm{HR}$ and SBP combinations, products or quotients in patients with CHF. The results of the present study provide several new findings on this issue. It was found that higher HR $\times$ SBP product $(\mathrm{DP})$ correlated negatively with CHF exacerbation risk in 6 -month observation period. Similarly, patients with higher $\mathrm{HR} \times \mathrm{DBP}$ product were at lower risk of $\mathrm{CHF}$ decompensation both in 3-month and 6 -month observation periods. The supposition was that those negative correlations are related to previously described reverse relationship between BP and HF outcome. No relationship was observed between: $\mathrm{DP}, \mathrm{HR} \times \mathrm{DBP}, \mathrm{HR} \times \mathrm{PP}$ products and mortality. There were no publications found which support the present observations. There were few conflicting studies examining the predictive role of DP in healthy or hypertensive populations $[17,18,40]$. Moreover, none of the calculated quotients impacted on MACE during follow up. No publications were found concerning this subject in patients with HF. There are some reports concerning the role of mean arterial pressure and heart rate quotient (PRQ) in myocardium hypoperfusion prediction. Buffington et al. [41] indicated that PRQ is an effective predictor of hypoperfusion of collateral-dependent myocardium. Mereu et al. [42] investigated HR/SBP quotient as predictor of neuromediated syncope. It has been revealed that $\mathrm{HR} / \mathrm{SBP}$ ratio may be a valuable tool to estimate the occurence of syncope. Further studies are needed to estimate the prognostic role of combining HR and $\mathrm{BP}$ in populations with $\mathrm{CHF}$.

\section{Limitation to the study}

The prognostic value strength of proposed risk stratification factors may be diminuated by the fact that the majority of patients received pharmacological treatment including antihypertensive drugs (ACE inhibitors or ARB, diuretics, beta-blockers) and negative chronotropic agents (digoxin, betablockers). Moreover, BP and HR values were not estimated by ambulatory BP monitoring but only through automatic several daytime BP measure- 
ments. However, the intention of this study was to verify the utility of simple BP measurements similar to those performed at home. Finally, the study population was small and the observation period short thus it may be difficult to extrapolate obtained results to general CHF populations.

\section{Conclusions}

This study revealed that DBP and DP, HR $\times$ $\times$ DBP products may be simple, achievable tools in the prediction of $\mathrm{HF}$ exacerbations in stable $\mathrm{CHF}$ patients in short-term observation. Moreover, a significant relationship was found between DBP value and 3-month mortality in this group of patients. None of the estimated products or quotients influenced mortality in the present study group.

\section{Conflict of interest: None declared}

\section{References}

1. Ponikowski P, Voors AA, Anker SD, et al. 2016 ESC Guidelines for the diagnosis and treatment of acute and chronic heart failure: The Task Force for the diagnosis and treatment of acute and chronic heart failure of the European Society of Cardiology (ESC)Developed with the special contribution of the Heart Failure Association (HFA) of the ESC. Eur Heart J. 2016; 37(27): 2129-2200, doi: 10.1093/eurheartj/ehw128, indexed in Pubmed: 27206819 .

2. Nessler J, Skrzypek A. Chronic heart failure in the elderly: a current medical problem. Pol Arch Med Wewn. 2008; 118(10): 572-580, indexed in Pubmed: 19112819.

3. Bjurman C, Holmström A, Petzold M, et al. Assessment of a multi-marker risk score for predicting cause-specific mortality at three years in older patients with heart failure and reduced ejection fraction. Cardiol J. 2015; 22(1): 31-36, doi: 10.5603/ /CJ.a2014.0017, indexed in Pubmed: 24526512.

4. Jarosz M, Wolańska D, Stolińska H, et al. Nutrition and lifestyle in patients pharmacologically treated due to hypertensionally treated due to hypertension. Cardiol J. 2016; 23(5): 491-496, doi: 10.5603/CJ.a2016.0049, indexed in Pubmed: 27439369.

5. Lee TT, Chen J, Cohen DJ, et al. The association between blood pressure and mortality in patients with heart failure. Am Heart J. 2006; 151(1): 76-83, doi: 10.1016/j.ahj.2005.03.009, indexed in Pubmed: 16368295.

6. Raphael CE, Whinnett ZI, Davies JE, et al. Quantifying the paradoxical effect of higher systolic blood pressure on mortality in chronic heart failure. Heart. 2009; 95(1): 56-62, doi: 10.1136/ /hrt.2007.134973, indexed in Pubmed: 18653573.

7. Grigorian-Shamagian L, Gonzalez-JuAnatey JR, Vazquez R, et al. Association of blood pressure and its evolving changes with the survival of patients with heart failure. J Card Fail. 2008; 14(7): 561-568, doi: 10.1016/j.cardfail.2008.03.006, indexed in Pubmed: 18722321.

8. Wright JT, Williamson JD, Whelton PK, et al. SPRINT Research Group. A Randomized Trial of Intensive versus Standard BloodPressure Control. N Engl J Med. 2015; 373(22): 2103-2116, doi: 10.1056/NEJMoa1511939, indexed in Pubmed: 26551272.
9. Bavishi C, Bangalore S, Messerli FH. Outcomes of Intensive Blood Pressure Lowering in Older Hypertensive Patients. J Am Coll Cardiol. 2017; 69(5): 486-493, doi: 10.1016/j. jacc.2016.10.077, indexed in Pubmed: 28153104.

10. McLaren DP, Jones R, Plotnik R, et al. Prior hospital admission predicts thirty-day hospital readmission for heart failure patients. Cardiol J. 2016; 23(2): 155-162, doi: 10.5603/CJ.a2016.0005, indexed in Pubmed: 26779968.

11. Palatini P, Julius S. Elevated heart rate: a major risk factor for cardiovascular disease. Clin Exp Hypertens. 2004; 26(7-8): 637644, indexed in Pubmed: 15702618.

12. Diaz A, Bourassa MG, Guertin MC, et al. Long-term prognostic value of resting heart rate in patients with suspected or proven coronary artery disease. Eur Heart J. 2005; 26(10): 967-974, doi: 10.1093/eurheartj/ehi190, indexed in Pubmed: 15774493.

13. Cowie MR, Fox KF, Wood DA, et al. Survival of patients with a new diagnosis of heart failure: a population based study. Heart. 2000; 83(5): 505-510, indexed in Pubmed: 10768897.

14. Swedberg K, Komajda M, Böhm M, et al. Ivabradine and outcomes in chronic heart failure (SHIFT): a randomised placebocontrolled study. Lancet. 2010; 376(9744): 875-885, doi: 10.1016/ /S0140-6736(10)61198-1, indexed in Pubmed: 20801500.

15. Gobel FL, Norstrom LA, Nelson RR, et al. The rate-pressure product as an index of myocardial oxygen consumption during exercise in patients with angina pectoris. Circulation. 1978; 57(3): 549-556, indexed in Pubmed: 624164.

16. Villella M, Villella A, Barlera S, et al. Prognostic significance of double product and inadequate double product response to maximal symptom-limited exercise stress testing after myocardial infarction in 6296 patients treated with thrombolytic agents. GISSI-2 Investigators. Grupo Italiano per lo Studio della Sopravvivenza nell-Infarto Miocardico. Am Heart J. 1999; 137(3): 443-452, indexed in Pubmed: 10047624.

17. Inoue R, Ohkubo T, Kikuya M, et al. Predictive value for mortality of the double product at rest obtained by home blood pressure measurement: the Ohasama study. Am J Hypertens. 2012; 25(5): 568-575, doi: 10.1038/ajh.2012.3, indexed in Pubmed: 22318510.

18. Schutte R, Thijs L, Asayama K, et al. Double product reflects the predictive power of systolic pressure in the general population: evidence from 9,937 participants. Am J Hypertens. 2013; 26(5): 665-672, doi: 10.1093/ajh/hps119, indexed in Pubmed: 23391621.

19. Brophy JM, Dagenais GR, McSherry F, et al. A multivariate model for predicting mortality in patients with heart failure and systolic dysfunction. Am J Med. 2004; 116(5): 300-304, doi: 10.1016/j. amjmed.2003.09.035, indexed in Pubmed: 14984814.

20. Lee DS, Austin PC, Rouleau JL, et al. Predicting mortality among patients hospitalized for heart failure: derivation and validation of a clinical model. JAMA. 2003; 290(19): 2581-2587, doi: 10.1001/ /jama.290.19.2581, indexed in Pubmed: 14625335.

21. Ghali JK, Kadakia S, Bhatt A, et al. Survival of heart failure patients with preserved versus impaired systolic function: the prognostic implication of blood pressure. Am Heart J. 1992; 123(4 Pt 1): 993-997, indexed in Pubmed: 1550009.

22. Lip GYH, Skjøth F, Overvad K, et al. Blood pressure and prognosis in patients with incident heart failure: the Diet, Cancer and Health (DCH) cohort study. Clin Res Cardiol. 2015; 104(12): 1088-1096, doi: 10.1007/s00392-015-0878-4, indexed in Pubmed: 26111867.

23. Berry M, Lairez O, Fourcade J, et al. Prognostic value of systolic short-term blood pressure variability in systolic heart failure. Clin Hypertens. 2016; 22: 16, doi: 10.1186/s40885-016-0051-z, indexed in Pubmed: 27413538. 
24. Sherazi S, McNitt S, Choudhary N, et al. Predictors of mortality in patients hospitalized for congestive heart failure with left ventricular ejection fraction $\geq 40$. Cardiol J. 2015; 22(4): 382-390, doi: 10.5603/CJ.a2015.0003, indexed in Pubmed: 25588532.

25. Lonn EM, Bosch J, López-Jaramillo P, et al. HOPE-3 Investigators. Blood-Pressure lowering in intermediate-risk persons without cardiovascular disease. N Engl J Med. 2016; 374(21): 2009-2020, doi: 10.1056/NEJMoa1600175, indexed in Pubmed: 27041480 .

26. Messerli FH, Mancia G, Conti CR, et al. Dogma disputed: can aggressively lowering blood pressure in hypertensive patients with coronary artery disease be dangerous? Ann Intern Med. 2006; 144(12): 884-893, indexed in Pubmed: 16785477.

27. McEvoy JW, Chen Y, Rawlings A, et al. Diastolic blood pressure, subclinical myocardial damage, and cardiac events: implications for blood pressure control. J Am Coll Cardiol. 2016; 68(16): 1713-1722, doi: $10.1016 /$ j.jacc.2016.07.754, indexed in Pubmed: 27590090.

28. Voors AA, Ouwerkerk W, Zannad F, et al. Development and validation of multivariable models to predict mortality and hospitalization in patients with heart failure. Eur J Heart Fail. 2017; 19(5): 627-634, doi: 10.1002/ejhf.785, indexed in Pubmed: 28247565 .

29. Uszko-Lencer NH, Frankenstein L, Spruit MA, et al. Predicting hospitalization and mortality in patients with heart failure: The BARDICHE-index. Int J Cardiol. 2017; 227: 901-907, doi: 10.1016/j.ijcard.2016.11.122, indexed in Pubmed: 27915084.

30. Rihal CS, Nishimura RA, Hatle LK, et al. Systolic and diastolic dysfunction in patients with clinical diagnosis of dilated cardiomyopathy. Relation to symptoms and prognosis. Circulation. 1994; 90(6): 2772-2779, indexed in Pubmed: 7994820.

31. Kalantar-Zadeh K, Block G, Horwich T, et al. Reverse epidemiology of conventional cardiovascular risk factors in patients with chronic heart failure. J Am Coll Cardiol. 2004; 43(8): 1439-1444, doi: 10.1016/j.jacc.2003.11.039, indexed in Pubmed: 15093881.

32. Cowie MR, Davidson L. Clinical perspective: the importance of heart rate reduction in heart failure. Int J Clin Pract. 2012; 66(8): 728-730, doi: 10.1111/j.1742-1241.2012.02968.x, indexed in Pubmed: 22805264.
33. Kjekshus J, Gullestad L. Heart rate as a therapeutic target in heart failure. Eur Heart J. 1999; 1(Suppl. H): H64-9.

34. McAlister FA, Wiebe N, Ezekowit JA, et al. Heart rate reduction and death in patients with heart failure. Ann Intern Med. 2009; 150: 784-94.

35. Ekman I, Chassany O, Komajda M, et al. Heart rate reduction with ivabradine and health related quality of life in patients with chronic heart failure: results from the SHIFT study. Eur Heart J. 2011; 32(19): 2395-2404, doi: 10.1093/eurheartj/ehr343, indexed in Pubmed: 21875859.

36. Zou C, Dong H, Wang F, et al. Heart acceleration and deceleration capacities associated with dilated cardiomyopathy. Eur J Clin Invest. 2016; 46(4): 312-320, doi: 10.1111/eci.12594, indexed in Pubmed: 26800852.

37. Cullington D, Goode KM, Zhang J, et al. Is heart rate important for patients with heart failure in atrial fibrillation? JACC Heart Fail. 2014; 2(3): 213-220, doi: 10.1016/j.jchf.2014.01.005, indexed in Pubmed: 24952686.

38. Li SJ, Sartipy U, Lund LH, et al. Prognostic significance of resting heart rate and use of $\beta$-Blockers in atrial fibrillation and sinus rhythm in patients with heart failure and reduced ejection fraction: findings from the swedish heart failure registry. Circ Heart Fail. 2015; 8(5): 871-879, doi: 10.1161/CIRCHEARTFAILURE. 115.002285, indexed in Pubmed: 26243796.

39. Sánchez-Gil J, Manzano L, Flather M, et al. RICA investigators. Combining heart rate and systolic blood pressure to improve risk stratification in older patients with heart failure: Findings from the RICA Registry. Int J Cardiol. 2017; 230: 625-629, doi: 10.1016/j.ijcard.2016.12.041, indexed in Pubmed: 28063667.

40. White WB. Heart rate and the rate-pressure product as determinants of cardiovascular risk in patients with hypertension. Am J Hypertens. 1999; 12(2 Pt 2): 50S-55S, indexed in Pubmed: 10090295.

41. Buffington CW, Sivarajan M, Bashein G. The quotient of mean arterial pressure and heart rate predicts hypoperfusion of collateral-dependent myocardium. J Cardiothorac Anesth. 1989; 3(1): 65-69, indexed in Pubmed: 2520642.

42. Mereu R, De Barbieri G, Perrone T, et al. Heart rate/blood pressure ratio as predictor of neuromediated syncope. Int J Cardiol. 2013; 167(4): 1170-1175, doi: 10.1016/j.ijcard.2012.03.115, indexed in Pubmed: 22503570. 